\title{
INTERCONNECTION OF WOMEN EPEE FENCERS OF DIFFERENT QUALIFICATION INDICATORS
}

\author{
Briskin Yuriy $^{1}$, Pityn Maryan ${ }^{1}$, Semeryak Zoryana ${ }^{1}$, and Vaulin Oleksandr ${ }^{1}$ \\ ${ }^{1}$ Department of olympic, professional and adaptive sport, Lviv State University \\ of Physical Culture, Ukrane
}

\section{SUMMARY}

It is set that discrepancy in the structure and content of correlational connections between indicators of technical and tactical kinds of training of women epee fencers of different qualification can allow to confirm about the need of educational and training correction with use of accents on the improvement of hits accuracy without attention decrease on other kinds of training of qualified sportsmen on the stage of specialized basic development and their training level approach to model indicators of high qualified women epee fencers..

Key Words: interconnection, qualification, technical training, women epee fencers.

\section{INTRODUCTION}

Rivalry level in main fencing competitions of Ukraine between women epee fencers in quite low. In the training system it can be related to low quality of training at previous stages of long-term improvement. (Кемлер, 1983; Шевчук 2007; Триперина 2004; Тышлер \& Рыжкова, 2010).

Ability to correct the orientation of accentuated increases of specialized load amount that happens at the stage of specialized basic development is determined by indicators interconnection of different parts of sportsmen training with consideration of factors that provide sport result.

So, solving prerequisites of actual scientific and practical task of technical and tactical sportsmen improvement on the stage of specialized basic development should be seen in setting the interconnections between indicators of technical training and other parts of women epee fencers of different qualification training and their characteristics.

Fencing refers to a group of combat arts with variant conditions of competitive activity that sets the priority in the structure of sportsmen training and abilities for effective realization of all technical and tactical actions (Кельер, 1983; Семеряк \& Смирновський, 2013; Турецкий, 1991). Main atten- tion of specialists in fencing in set on the questions that are related to the structure and content of competitive activity in different kinds of weapons, improvement of different kinds of fencers training and their control that basically solve the question of sportsmen training and only partly solve the question of theoretical and methodological aspects of fencing training (Кемлер, 1983; Семеряк \& Смирновський, 2013; Шилова, 1992; Тышкер \& Мовшович, 1993; Тышлер \& Рыжкова, 2010).

This research is performed in according to topic 2.8 "Improvement of sportsmen training in groups of sports" of Consolidates plan of scientific research work in field of physical culture and sport on 20112015 years.

Aim of the research is to determine interconnections between indicators of technical training and other parts of women epee fencers of different qualification training

\section{METHODS}

Theoretical analysis and generalization, pedagogical observation, methods of mathematical statistics.

Into the research were involved 13 high qualified women epee fencers from national fencing team of 
TABLE 1

Indicators interconnection of technical training with other

parts of high qualified women epee fencers training $(n=13)$.

\begin{tabular}{|c|c|c|c|c|c|c|c|c|c|c|c|}
\hline & 1 & 2 & 3 & 4 & 5 & 6 & 7 & 8 & 9 & 10 & 11 \\
\hline 12 & .63 & .58 & .36 & .46 & .05 & -.24 & -.20 & .45 & .26 & -.27 & .22 \\
\hline 13 & -.01 & -.33 & .24 & .29 & -.02 & .59 & .36 & .51 & .14 & -.36 & .56 \\
\hline 14 & -.25 & -.60 & .20 & .18 & .06 & -.17 & .22 & .14 & .04 & .20 & .25 \\
\hline 15 & .11 & .59 & .11 & .21 & .60 & -.40 & -.03 & .35 & .23 & .02 & .32 \\
\hline 16 & .08 & .26 & -.57 & .32 & -.70 & .05 & .03 & -.51 & .40 & .08 & .00 \\
\hline 17 & -.44 & -.06 & .03 & .53 & -.59 & -.10 & .12 & -.35 & -.05 & .09 & -.14 \\
\hline 18 & -.45 & -.59 & .26 & .32 & -.04 & -.12 & -.06 & .20 & -.15 & -.44 & -.17 \\
\hline 19 & -.42 & -.68 & .09 & .19 & -.12 & -.22 & .56 & -.23 & -.10 & -.17 & -.05 \\
\hline 20 & -.13 & .23 & -.62 & -.62 & -.75 & -.37 & .01 & -.24 & -.45 & -.61 & -.48 \\
\hline 21 & -.26 & -.49 & -.44 & .07 & -.63 & .39 & -.35 & .01 & -.56 & .04 & -.42 \\
\hline 22 & -.28 & .36 & -.29 & -.51 & .23 & .34 & .19 & .64 & .01 & -.33 & .30 \\
\hline 23 & -.06 & .00 & .09 & -.30 & -.57 & -.58 & .06 & -.01 & .26 & .17 & .23 \\
\hline 24 & .01 & -.11 & -.03 & -.60 & -.62 & -.56 & .08 & -.07 & .03 & .00 & .01 \\
\hline 25 & .05 & -.11 & .10 & -.21 & -.69 & -.64 & -.04 & -.02 & .05 & .00 & .00 \\
\hline 26 & -.02 & .12 & .12 & .13 & .01 & -.42 & .42 & .08 & .16 & .58 & -50 \\
\hline 27 & -.37 & -.43 & .21 & .28 & -.06 & .13 & -.03 & -.20 & -.18 & -.30 & -.33 \\
\hline 28 & -.15 & .33 & .45 & .20 & .35 & .07 & .25 & -.10 & .16 & .41 & .28 \\
\hline 29 & .03 & -.41 & -.07 & .14 & -.26 & .05 & -.14 & -.35 & -.50 & -.55 & -.73 \\
\hline 30 & -.40 & .26 & .28 & -.05 & .43 & -.02 & .31 & .27 & .24 & .34 & .52 \\
\hline 31 & .27 & -.05 & -.02 & -.01 & -.01 & .24 & -.52 & -.17 & -.04 & -.62 & -.53 \\
\hline 32 & .65 & .16 & -.11 & -.53 & .49 & -.24 & .13 & .49 & .10 & -.06 & .39 \\
\hline 33 & .53 & .40 & .05 & -.29 & .42 & -.28 & .00 & .69 & .10 & .03 & .44 \\
\hline 34 & -.30 & -.14 & .10 & .26 & -.17 & .48 & -.18 & .61 & .05 & -.33 & -.48 \\
\hline 35 & -.02 & -.32 & -.20 & -.12 & -.11 & -.47 & .27 & .30 & -.16 & .46 & .34 \\
\hline 36 & .30 & .20 & -.18 & .02 & -.26 & .32 & -.06 & .72 & .06 & -.52 & .20 \\
\hline 37 & .35 & .19 & -.11 & -.02 & -.12 & .29 & -.32 & .60 & .12 & -.34 & .15 \\
\hline
\end{tabular}

Legend: $\mathrm{p} \leq .05$ with $\mathrm{r}_{\mathrm{cr}}=.55 ; \mathrm{p} \leq .01$ with $\mathrm{r}_{\mathrm{cr}}=.68$; indicators of control exercises;

Horizontal: 1. - "Lounge from sitting with target hit" (10 times), st. un.; 2. - "Jump, lounge with target hit" (10 times), st. un.; 3. - "Lounge, second lounge in two targets", 10 times, st. un.; 4. - Effectiveness of first lounge; 5. - Effectiveness of second lounge; 6. - "Hits frequency at place, 10 sec" (amount); 7. - Sector 1 (amount) ; 8. - Sector 2 (amount); 9. - Sector 3 (amount); 10. - Sector 4 (amount); 11. - "Hits frequency by trunk sectors, 40 sec" (amount).

Vertically: 12. - jump into length from a place $(\mathrm{cm}) ; 13$. - ball $(2 \mathrm{~kg})$ throw $(\mathrm{cm}) ; 14$. - cross twine, distance to the floor $(\mathrm{cm}) ; \mathbf{1 5}$. - fencing lounge $(\mathrm{cm}) ; 16$. - reproduction of fencing lounge at $75 \%(\mathrm{~cm}) ; 17$. - reproduction of fencing lounge at $50 \%(\mathrm{~cm}) ; 18$. - shuttle run $4 \times 14 \mathrm{M}$ (forward - face looks forward, return with back forward), s; 19. - running $14 \mathrm{~m},(\mathrm{~s}) ; 2$. - fencing piste passing with closed eyes $14 \times 1 \mathrm{~m},(\mathrm{~s}) ; 21$. - exit from corridors (amount); 22. - coordination by profile, (s); 23. - amount of touches by coordination by profile (amount); 24. - "big lap" (15 sec), touches (amount); 25. - "small lap", (15 s), touches (amount); 26. - simple visual-motor reaction (ms); 27. - mistakes during simple visual-motor reaction (amount); 28. - choosing reaction (ms); 29. - mistakes during choosing reaction (amount); 30. - distinction reaction (ms); 31. - mistakes during distinction reaction (amount); 32. - reaction on a moving object (ms); 33. - amount of accurate reproduction of reaction on a moving object (amount); 34. - amount of advances during reaction on a moving object (amount); 35. - amount of delays during reaction on a moving object (amount); 36. - amount of touches during tapping test (times); 37. - average frequency by tapping test $(\mathrm{Hz})$. 
Ukraine and 32 qualified fencers from sport schools of Lviv, Ternopil and Uzhgorod. Correlational interconnections were based on the analysis of eleven indicators pf technical training and twenty six indicators of other parts of training that included specialized physical training and psychophysical training. Pedagogical observations by the parts of training of women epee fencers were made during January 2013.

\section{RESULTS AND DISCUSSION}

Near the study of qualification and determined features of different parts of women epee fencers training was set a need to study structure and content of interconnections between technical training and other parts of training of different qualification sportsmen (Table 1).

Correlation analysis showed that despite the exclusiveness of the sample of high qualified women epee fencers there are reliable correlational interconnection (totally 35 positions) between indicators of different parts of training.

Results of a control exercise "lounge from sitting with target hit" of high qualified women epee fencers had only two interconnections with results of " jump into length from a place" ( $r=.63)$ and reaction on a moving object $(r=.65)$. So, in the first case we can see a positive dynamic of indicators showing that high qualified sportsmen can demonstrate bigger displays of explosive power and can provide more qualified performance of a fencing lounge that is included into the content of control exercise. Negative interconnection with indicators of reaction on a moving object on our opinion is related with to the problem of lounge performance. Lounge from sitting with target hit is related to relatively simple exercises for high qualified women epee fencers and doesn't need the displays of this kind of complex reaction.

Note, that in results of a control exercise "jump, lounge with a target hit" are recorded five reliable ( $p \leq .05-.01)$ positive interconnection of medium density with results of control exercises that are used for identification of specialized physical training: "jump into length from a place" $(r=.58)$; "cross twine" $(r=-.60)$, fencing lounge $(r=.59)$; shuttle run $4 \times 14 \mathrm{~m}(\mathrm{r}=-.59)$ and "running $14 \mathrm{~m}$ " $(r=-.68)$. Received data is quite predictable that is related to the same internal and external sportsmen muscle structure during this exercise. For qualified analysis and effective performance of "jump, lounge with a target hit" exercise sportsmen must have enough level of explosive strength that is shown in control exercise (long jump from a place). Besides the distance for a fencing hit is determined by the level of hips joint mobility (control exercises "cross twine" and "fencing lounge"). The interconnection justification of "shuttle running $4 \times 14 \mathrm{~m}$ " and "running $14 \mathrm{~m}$ " also is determined by dominated displays of lower extremities explosive strength in these exercises, especially in situation of start and change of the direction of motion (Шилова, 1992; Тышлер \& Мовшович, 1993; Тышлер \& Рыжкова, 2010).

For the results of a control exercise "lounge, second lounge in two targets" were observed two interconnections - with "reproduction of $75 \%$ fencing lounge" and "fencing piste passing with closed eyes $14 \times 1 \mathrm{~m}$ " ( $\mathrm{r}=$ from -.57 till -.62 with $p \leq .05)$. The existence of such interconnections allows to affirm that for the contingent of high quailed women epee fencers the performance of control exercise "lounge, second lounge in two targets" is characterized by the displays of coordination abilities of dynamic character and the rating and regulation of muscle efforts that complements scientific data that was received by specialists before (Кемлер, 1983; Тышлер \& Мовшович, 1993; Триперина, 2004).

The same amount of reliable interconnections was set between the results of first lunge in control exercise "lounge, second lounge in two targets" and "fencing piste passing with closed eyes $14 \mathrm{x} 1 \mathrm{~m}$ " (time of performance) $-r=-.62(p \leq .05)$ and contact tremography ("big circle") $-r=-.60$ ( $\mathrm{p} \leq .05)$. Received coefficients meaning show that high qualified sportsmen that better perform first hit in control exercise "lounge, second lounge in two targets" quicker overcome with closed eyes a fencing piste and more qualified withstand static load. It can be confirmed that qualified level of sportsmen training is displayed on their confident organization of movement activity in heavy coordinated exercises that transferred on the conditions of competitive activity can give benefits in attack and counterattack actions.

With it, the results of the second lounge in exercise "lounge, second lounge in two targets" was fixed by us the biggest between other indicators correlation of reliable interconnections (eight). They exist with the indicators of control exercises that are related to specialized physical training ("fencing lounge", "reproduction of $75 \%$ fencing lounge", "reproduction of $50 \%$ fencing lounge", "fencing piste passing with closed eyes" and "exit from corridors" $-r=$ from .59 till .70 with $p \leq .05-.01$; and psychophysical qualities ("profile", "big circle", "small circle"). All they have a positive focus. This means that in conditions of a control exercise "lounge, second lounge in two targets" and the second hit for high qualified women epee 
TABLE 2

Indicators interconnection of technical training with other parts of qualified women epee fencers training $(n=32)$

\begin{tabular}{|c|c|c|c|c|c|c|c|c|c|c|c|}
\hline & 1 & 2 & 3 & 4 & 5 & 6 & 7 & 8 & 9 & 10 & 11 \\
\hline 12 & -.03 & .06 & .40 & .38 & .08 & .09 & .19 & -.14 & .17 & .28 & .24 \\
\hline 13 & .02 & .38 & .07 & -.05 & .15 & .10 & -.13 & .35 & .15 & -.04 & .10 \\
\hline 14 & .05 & -.30 & -.35 & -.10 & -.46 & .04 & .14 & -.16 & -.16 & -.18 & -.14 \\
\hline 15 & -.17 & .18 & .26 & .12 & .37 & -.14 & -.18 & .23 & .11 & .05 & .06 \\
\hline 16 & -.10 & .03 & .10 & .14 & .02 & -.09 & -.12 & .26 & -.02 & .11 & .08 \\
\hline 17 & -.10 & -.22 & .13 & .22 & .02 & -.19 & -.02 & -.03 & -.01 & -.06 & -.05 \\
\hline 18 & .14 & .11 & .19 & .18 & .01 & -.08 & -.02 & .01 & .43 & .17 & .22 \\
\hline 19 & -.01 & -.29 & -.49 & -.28 & -.49 & -.09 & .00 & -.10 & .09 & .38 & .18 \\
\hline 20 & -.08 & .05 & -.52 & -.44 & -.33 & .10 & -.03 & -.29 & .11 & .10 & -.03 \\
\hline 21 & -.07 & -.11 & -.14 & -.22 & .06 & .04 & .01 & -.09 & -.06 & .07 & -.01 \\
\hline 22 & .01 & .04 & .02 & .07 & .01 & -.31 & -.43 & .14 & -.09 & -.03 & -.19 \\
\hline 23 & .28 & .05 & -.03 & -.08 & .11 & .11 & .04 & .20 & .10 & .01 & .13 \\
\hline 24 & .02 & .12 & .16 & .14 & -.02 & -.01 & .20 & -.30 & .07 & .16 & .09 \\
\hline 25 & -.23 & .00 & -.21 & -.17 & -.06 & -.29 & -.09 & -.55 & -.36 & -.28 & -.49 \\
\hline 26 & .06 & -.30 & -.09 & -.08 & -.04 & .15 & .15 & .34 & .08 & .16 & .29 \\
\hline 27 & .09 & -.09 & .11 & .00 & .04 & -.05 & .09 & -.32 & -.11 & .04 & -.09 \\
\hline 28 & .02 & -.33 & -.32 & -.18 & -.21 & .08 & .08 & .05 & .00 & .13 & .12 \\
\hline 29 & .12 & .38 & .22 & .11 & .17 & .00 & .05 & -.33 & -.08 & -.23 & -.23 \\
\hline 30 & -.21 & -.30 & -.16 & -.14 & -.02 & -.17 & -.07 & .03 & -.15 & -.03 & -.09 \\
\hline 31 & .21 & .49 & .32 & .22 & .18 & .01 & .05 & -.15 & -.02 & -.27 & -.17 \\
\hline 32 & -.02 & -.33 & -.28 & -.19 & -.26 & .04 & .25 & -.06 & .17 & .24 & .27 \\
\hline 33 & .31 & .03 & .23 & .30 & -.07 & -.07 & .13 & -.11 & .07 & -.03 & .03 \\
\hline 34 & -.16 & .05 & -.02 & -.10 & .13 & .00 & -.10 & -.23 & -.38 & -.14 & -.32 \\
\hline 35 & -.12 & -.08 & -.20 & -.17 & -.07 & .06 & -.02 & .32 & .31 & .17 & .29 \\
\hline 36 & -.04 & -.27 & -.13 & -.17 & -.08 & .01 & .06 & .03 & .03 & .01 & .05 \\
\hline 37 & -.08 & -.29 & -.10 & -.18 & .05 & .12 & .24 & -.11 & -.08 & .13 & .11 \\
\hline
\end{tabular}

Legend: $\mathrm{p} \leq .05$ with $\mathrm{r}_{\mathrm{cr}}=.35 ; \mathrm{p} \leq .01$ with $\mathrm{r}_{\mathrm{cr}}=.45$; indicators of control exercises;

Horizontal: 1. - "Lounge from sitting with target hit" (10 times), st. un.; 2. - "Jump, lounge with target hit" (10 times), st. un.; 3. - "Lounge, second lounge in two targets", 10 times, st. un.; 4. - Effectiveness of first lounge; 5. - Effectiveness of second lounge; 6. - "Hits frequency at place, 10 sec" (amount); 7. - Sector 1 (amount) ; 8. - Sector 2 (amount); 9. - Sector 3 (amount); 10. - Sector 4 (amount); 11. - "Hits frequency by trunk sectors, 40 sec" (amount).

Vertically: 12. - jump into length from a place $(\mathrm{cm}) ; 13$. - ball $(2 \mathrm{~kg})$ throw $(\mathrm{cm}) ; 14$. - cross twine, distance to the floor $(\mathrm{cm}) ; \mathbf{1 5}$. - fencing lounge $(\mathrm{cm}) ; 16$. - reproduction of fencing lounge at $75 \%(\mathrm{~cm}) ; 17$. - reproduction of fencing lounge at $50 \%(\mathrm{~cm}) ; 18$. - shuttle run $4 \times 14 \mathrm{M}$ (forward - face looks forward, return with back forward), s; 19. - running $14 \mathrm{~m},(\mathrm{~s}) ; 20$. - fencing piste passing with closed eyes $14 \times 1 \mathrm{~m},(\mathrm{~s}) ; 21$. - exit from corridors (amount); 22. - coordination by profile, (s); 23. - amount of touches by coordination by profile (amount); 24. - "big lap" (15 sec), touches (amount); 25. - "small lap", (15 s), touches (amount); 26. - simple visual-motor reaction (ms); 27. - mistakes during simple visual-motor reaction (amount); 28. - choosing reaction (ms); 29. - mistakes during choosing reaction (amount); 30. - distinction reaction (ms); 31. - mistakes during distinction reaction (amount); 32. - reaction on a moving object (ms); 33. - amount of accurate reproduction of reaction on a moving object (amount); 34. - amount of advances during reaction on a moving object (amount); 35. - amount of delays during reaction on a moving object (amount); 36. - amount of touches during tapping test (times); 37. - average frequency by tapping test $(\mathrm{Hz})$. 
fencers is characterized a displays of complex qualities that are based on the displays of several coordination qualities and their long ensuring.

For group of technical training control indicators that are connected with hits frequency were observed isolated and scattered interconnections indicators of control exercises from specialized physical training and psychophysical qualities, such as: positive - ball $(2 \mathrm{~kg})$ throw $(\mathrm{cm})$ that can be related to the use of big muscles of upper ling during performance $(r=$ from .56 till .59 with $p \leq .05)$ and other indicators: "fencing piste passing with closed eyes", "exit from corridors", mistakes amount during options "profile", "big lap", "small lap", mistakes during choosing reaction, mistakes during distinction reaction, amount of accurate reproduction of reaction on a moving object $(r=$ from .56 till .69 with $p \leq .05-.01)$. It shows on an absence of clear factors that provide the results of this control exercises from technical training of women epee fencers from the side of specialized physical training and psychophysical qualities.

Along the same was fixed some negative interconnections with results of control exercises "running $14 \mathrm{~m}$ ", time for coordination by profile and simple visual-motor reaction ( $r=$ from .56 till .64 with $p \leq$ $.05)$. It can be related with the frequency of moves in this exercises that doesn't have a determining value for the control exercise result formation.

At the same time, structure and content of correlational interconnections of technical and other parts of qualified women epee fencers training on the stage of specialized basic development showed on the presence of significant differences (Table 2). In total are fixed less amount of reliable interconnections of different level of density ( 20 positions). Note that between this indicators of technical training as the result of control exercises "lounge from sitting with target hit" and "hits frequency at place for 10 seconds" with indicators of other parts of training didn't show any reliable correlational interconnections $(r=$ from .00 till .31 with $p>.05$ ).

Along the same for the result of control exercise "jump, lounge with a target hit" are fixed three reliable $(p \leq .05-.01)$ interconnections of low and medium level of density. With indicators of control exercise "ball (2 kg) throw" ( $r=.38)$; mistakes during choosing reaction $(r=.38)$, mistakes during distinction reaction $(r=.49)$. Herewith, if in first case it can be related to new trends. Meaning that sportsmen with higher results at the "jump, lounge with a target hit" also demonstrate higher indicator in the exercise "ball $(2 \mathrm{~kg})$ throw. In second and third case is observed a negative trend. It means that qualified sportsmen spend more functional efforts during performance of said exercise ("jump, lounge with a target hit") demonstrate positive transfer on "ball (2 kg) throw" and this ruins the accuracy of rating and regulation of muscle efforts that is confirmed by higher amount of mistakes in choosing and distinction reactions.

With the results of control exercise "lounge, second lounge in two targets" are registered four reliable positive correlational interconnections in indicators of specialized physical training (results of long jump from a place, cross twine, running $14 \mathrm{~m}$, fencing piste passing with closed eyes $-r=$ from .35 till .52 with $p$ $\leq .05-.01)$. This on our opinion is logical because specificity of physical qualities display and structure and content of control exercise from determination of technical training are similar. In fact it is formed from components that are provided by displays of specialize physical qualities.

A minor amount of interconnections are fixed for such indicators as first and second lounge in exercise "lounge, second lounge in two targets" (two and three respectively). In first case this are two positive interconnections with the result of long jump from a place and fencing piste passing with closed eyes $(r=$ from .38 till .44 with $p \leq .05$ ). In second case - results of a control exercise "cross twine", "fencing lounge" and "running $14 \mathrm{~m}$ " ( $r=$ from .37 till .49 with $p \leq$ $.05-$.01). It shows that for qualified women epee fencers on the stage of specialized basic development are characterized is the domination in the structure of training properly the specialized physical qualities, and not the technical skills. Besides, we should note that the providing factors during the performance of first and second hits that they are performed with the expense of different structure of physical qualities. This places demands for concentrated influence on specialized training of qualified sportsmen that is related with the use of targeted and successful technical and tactical actions and the consideration of the need of its repeated character.

As in the case with high qualified women epee fencers for the group of indicators that control technical training with the hits frequency were observed isolated and scattered interconnections between indicators of control exercises with specialized physical training and psychophysical qualities. Between them we should select coordinamometry ("small circle") with the results that set positive interconnections of total result in exercise "hits frequency by trunk sectors, $40 \mathrm{sec}$ " and separate sectors - sector 2 and sector 3 $(r=$ from -.36 till -.55 with $p \leq .01)$. This confirms that achieving of the result by thus group of control 
exercises provides the existence of strong nervous system in qualified sportsmen.

Along the same for frequency indicators of exercises are found separate reverse (negative interconnections. Is found that the higher amount (frequency) of hits by separate sectors is negatively connected with results of shuttle run $4 \times 14 \mathrm{~m}(r=.43$ with $p \leq$ $.01)$; running $14 \mathrm{~m}(r=.38$ with $p \leq .05)$ and amount of advances during reaction on a moving object $(r=$ -.38 with $p \leq .05$ ), that need further study.

\section{CONCLUSION}

Are set inconsistencies in the structure and content of correlational interconnections between indicators of technical and other parts of women epee fencers training of different qualification.

There is a need for correction of educational and training process with accentuated improvement of hits accuracy of qualified sportsmen on the stage of specialized basic development and their training level approach to model indicators of women epee fencers of high qualification.

Prospects of further research provide the building of a technical and tactical training program for qualified women epee fencers.

\section{REFERENCES}

Кемлер, В. С. (1983). Теоретические основы спортивной тактики [Theoretical basis of sport tactic]. In Fencing articles collection, 37-39.

Семеряк, 3. С., \& Смирновський С. Б. (2013). Техніко-тактична піАготовка фехтувальників на шпагах: стан та перспективи досліджень [Technical and tactical training of epee fencers: conditions and prospects of research]. Young Sport Science of Ukraine: col. of scientific works in $p$ h. cul, 17(1), 239-244.

Триперина, Т. (2004) Индивидуализация технико-тактического совершенствования квалифицированных фехтовальщиков на рапирах 17-19 мет [ndividualization of technical and tactical improvement of foil fencers 17-19 y.o.]. Retrved from http://www. disszakaz.com/catalog/262492.html

Турецкий, Б. В. (1991). Стили боевой Аеятельности фехтовальщиков [Competitive activity styles in fencing]. In Researches of system individualization, 120 - 121.

Тышлер, А. А., \& Мовшович, А. А. (1993). Методы технико-тактического совершенствования в фехтовании [Methods of technical and tactical improvement in fencing] Theory and practice of physical culture, 4, 27-28.

Тышлер, А. А., Мовшович, А. А., \& Бочарникова, А. Г. (1985) Критерии оценки технико-тактического мастерства [Criteria's of technical and tactical skills]. In Fencing articles collection, 34-36.

Тышкер, А. А., \& Рыжкова, А. Г. (2010). Фехтование. Технико-тактическая и функциональная тренировка. [Fencing. Technical, tactical and functional training]. Academic project.

Шевчук, Е. Н. (2007) Состояние проблемы технико-тактической подготовки квалифицированных фехтовальщиков [The technical and tactical training problem of qualified fencers]. XI Inter. sci. congress Modern Olympic sport for all (pp. 56-59) Minsk, Belarus.

Шилова, И. М. (1992) Модельные характеристики мичности квалифицированных фехтовальщиц [Model characteristics of qualified fencers]. In Materials of scientific conference for 1990-91(pp. 73-74). Omsk, Russia.

Received: February 23, 2015

Revision received: Jun 1, 2015

Accepted: Jun 27, 2015

Correspondence to: Maryan Pityni Lviv State University of Physical Culture,

Kostyushka str. 11

Ukraine, Lviv, zip code 79000 Phone:

E-mail: pityn7@gmail.com 